\title{
Research on Radial GIS Substation Design
}

\author{
Sun Lin ${ }^{1}$, Yuan Ting ${ }^{1}$, Huang Hongda ${ }^{1}$, Ding Yixin ${ }^{2}, \mathrm{Mu}$ Jinglong $^{2}, \mathrm{Zu} \mathrm{Bo}^{2}$, \\ Guan Chunmei ${ }^{2}$, Wang Kaizhi' ${ }^{2}$ Liu Wei ${ }^{2}$, Liu Ren², Wu Yaowei ${ }^{2}$, Han Lin ${ }^{2}$ \\ ${ }^{1}$ Panjin Power Supply Company, Liaoning Electric Power Company Limited, State Grid, China, \\ ${ }^{2}$ Fushun Power Supply Company, Liaoning Electric Power Company Limited, State Grid, China, \\ fushunpowersupply@163.com
}

Keywords: GIS combination of appliances, substation, radiating, single bus, Double bus

\begin{abstract}
By analyzing large GIS substation hub horizontally style, typical sub-voltage electrical layout design, grading flat and interior layer, sub-voltage, level of body building. Discuses the principles of the annular radial GIS substation and square radial GIS substation layout design. Generally large hub substation $110 \mathrm{kV}, 220 \mathrm{kV}$ GIS equipment's most used single bus-bar or double bus segment wiring. Describes the single bus-bar connection are simple, economical and convenient features, suitable for $110 \mathrm{kV}, 220 \mathrm{kV}$ substation level 4 back lines. Double bus segment in turn facilitate maintenance bus wiring, flexible scheduling, expansion of convenience, ease of testing. Suitable for $110 \mathrm{kV}, 220 \mathrm{kV}$ line above Level 6 back substation.
\end{abstract}

\section{Introduction}

According to the State Grid Corporation of smart grid deployment planning, research a way to meet customer needs and taking into account the optimization of the grid structure of the new substation layout design. Meet the future needs of the smart grid development. Design a radial GIS substation. Take into account the existing substation GIS substation layout design and many other advantages, but also a new GIS substation layout scheme. The program meets the transport equipment, installation, overhaul and test basic electrical design requirements and related maintenance requirements. The program must also consider laying power cables, overhead lines direction, control and protection panel layout, and other factors[1-3].

GIS substations are arranged radically large outdoor GIS substation layout design. Radial GIS substation area is half the existing GIS substation footprint. Flexible, layered design of the inlet and outlet more suited to the new area of smart grid construction and management.

\section{Technical solutions}

(1) Infrastructure layout

Radial GIS substation platforms have the upper and lower platforms. The upper and lower platforms work platforms for square or circular hollow structure. Set between the upper platforms pillar platform and lower operating platforms. H-type platform pillars, door frame are square-shaped shape, spacing the main equipment in H-pillar above the installation of high-voltage equipment. Effectively ensures the basic stability of the device operation[4].

Set on the upper frame radial GIS substation platforms. Insulator string hangs in the frame. A barrier layer is provided in a tiered arrangement and intervals of the upper and lower bus bar bus.

(2) Electrical layout

In the ring bus layout design will $220 \mathrm{KV}$ and $66 \mathrm{KV}$ layered arrangement. Wherein $220 \mathrm{KV}$ devices spaced in the upper bus bar, 66KV device disposed in the lower interval of the bus.

Bus radial GIS substation platforms simultaneously set in the upper and lower platforms. Each bus equipped with reserved space for export. Both ends of each bus have a fracture. Bus fracture dimensions and substation entrance road width match.

Radial GIS substation will replace the existing linear bus GIS circular or square bus. Bus fixed installation angle straight section bus bars[5]. 
On the lower storey voltage combination of electrical and low voltage electrical combination arranged are in a hierarchical arrangement.

Two main transformer stations were installed on both sides of the road substation. After the high-voltage side of the transformer bushing into the line after the main transformer installed at the first upper platform, a main switch bushing drainage wire leads into the primary side of the transformer high-voltage bushing. After high voltage transformer low voltage secondary leads from the transformer low voltage side of the casing, through drainage wire, introduced II main transformer of the underlying platform, the second main switch.

(3) Building body master layout

Main Building body and capacitor bank room set in the hollow square platform location or ring platform. The radial GIS substation layout is in Figure 1.

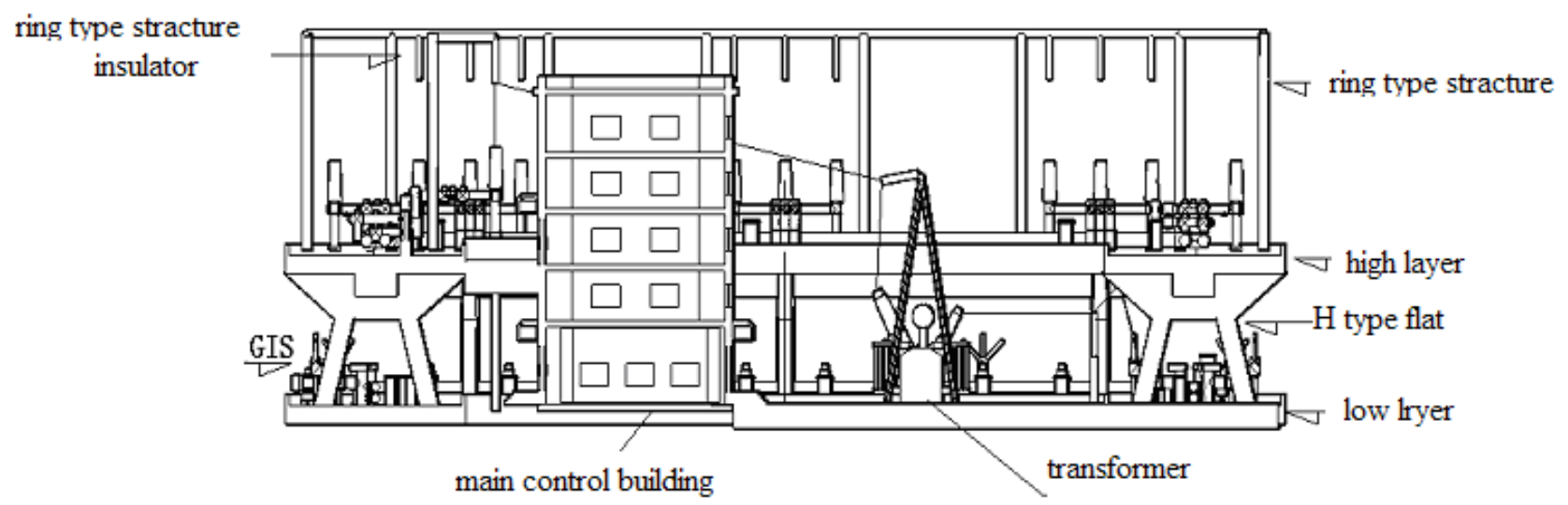

Figure 1 The radial GIS substation layout

\section{Technical advantages}

(1) Reduce the area

A typical example of $220 \mathrm{kV}$ GIS substation: 74 meters long, 162 meters wide, the calculated area of 11,988 square meters. After using ring radial GIS layout design, the ring diameter $75 \mathrm{~m}$, the calculated annular area of 4415 square meters, according to the square side length of 75 meters, the calculated area of 5625 square meters.

(2) Inlet, outlet broad corridor

For example a typical $220 \mathrm{kV}$ GIS substation in an area: $220 \mathrm{kV}$ electrical design and installation of a 13-return interval, $66 \mathrm{kV}$ and 27 back to the design and installation of electrical interval. After using ring radial GIS layout design, 220-kilovolt electrical interval back to 17, $66 \mathrm{kV}$ electrical intervals back to 30-60.

(3) Line, outlet wired flexible

With the rapid development of smart grid places, as well as a variety of clean energy and renewable energy to the grid increased demand, the line can be round, qualifying hub substation layout design, more suitable for future smart grid construction.

With layered annular arrangement, layered ring bus in each direction can be flexibly adjusting incoming and outgoing arrangement according to user needs.

Substation layout using radial inlet outlet, can effectively save money to build overhead lines. After the set being reduced to a certain urban layout program is to optimize overall grid structure is built kilometers of overhead lines by about $10 \%$. Hub substation construction is to reduce the number of $1 / 5$. Save money to build several billion RMB. Annual saved of a billion RMB of line loss and maintenance funds.

(4) Avoid overhead lines staggered across the line

$220 \mathrm{kV}$ GIS combination of electrical outlet spacing greater than 66kV GIS combination electrical outlet interval. Radically arranged hierarchically layout in staggered back, 220kV GIS combination of electrical outlet and 66kV GIS layered combination of electrical outlet was installed. The new electrical layout program is to ensure that the voltage level of the qualifying meet at a safe distance 
from the electrical design. Use of a radial linear dispersion this feature ensures the feasibility and the set of innovative solutions.

The high and low voltage wires across the line problem is now practical problems to be faced in the grid layout. Because of the design has been adopted into the substation, and outlet two symmetrical layout design direction. When you need different directions into and out of the line and network design requires the use of cross-wire design. Across the line, whether large-scale structure in the installation, maintenance and operation, are considered unsafe accidents grid structure of the weak link. GIS substation layout design using a radial grid structure optimization, the existence of these problems can be solved fundamentally.

\section{The main advantage of GIS equipment}

(1) Small footprint, covering general $220 \mathrm{kV}$ GIS equipment is $37 \%$ of the conventional device; $110 \mathrm{kV}$ GIS equipment covers an area of about $46 \%$ of the conventional device. Meet the basic national policy of conservation land, reducing the land acquisition, demolition, compensation and other expensive upfront costs.

(2) Because GIS equipment components are fully enclosed and therefore not subject to pollution, salt spray, humidity and other environmental impact. Conductive portion of the housing are GIS equipment shielding, grounding. Radiation conductor generated electric field interference, noise circuit breaker are shielded enclosure. GIS equipment is securely mounted on the basis of embedded parts, products, low center of gravity, high strength, excellent seismic performance, especially suitable for use in city centers or residential areas. Compared with conventional equipment, GIS is easier to meet the urban environmental requirements.

(3) $\mathrm{SF}_{6}$ gas as insulating medium, the gas itself does not burn, fire performance. Having excellent electrical insulation performance and arc extinguishing properties are safe and reliable operation, low maintenance, long maintenance cycle, suitable for unmanned substation, to reduce personnel efficiency purposes.

(4) Short construction period. Each element of versatility GIS equipment, the use of modular structure, assembled in a transport unit, transported to the construction site in place fixed. Work-site installation has reduced by about $80 \%$.than conventional equipment

\section{Conclusion}

Radial GIS substation layout design more suitable for installation in the heart of the city, area. The design of the original ladder typical grid layout designed to fill a new grid layout suitable for radial GIS substation operation. It can meet the future needs of the smart grid layout, with enormous economic and social benefits.

\section{References}

[1] Guo Ricai, Yuan Zhaoxiang, Li Jinbao.France, South Korea, the typical substation design and its Enlightenment on China's power grid project [J]. Grid technology, 2006

[2] Guo Ricai, Li Jinbao, Li Ming. Typical Design Research and Application 500 (330) kV substation [J]. Power Technology, 2005

[3] State Grid Corporation of $220 \mathrm{kV}$ and $110 \mathrm{kV}$ substation typical design working group. State Grid Corporation of the typical $110 \mathrm{kV}$ substation design (2005 edition) [Z]. Beijing: State Grid Corporation, 2005

[4] DL/T5218-2005. $220 \mathrm{kV} 500 \mathrm{kV}$ substation design specification [S]. 2005

[5] DLGJ25-1994. Substation preliminary design depth of content provision [S]. 1994 